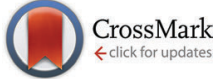

Cite this: Phys. Chem. Chem. Phys., 2015, 17, 11161

Received 6th March 2015, Accepted 31st March 2015

DOI: $10.1039 / c 5 c p 01337 b$

www.rsc.org/pccp

\title{
LiTFSI in 1-butyl-1-methylpyrrolidinium bis(fluorosulfonyl)amide: a possible electrolyte for ionic liquid based lithium ion batteries
}

\author{
Abhishek Lahiri, ${ }^{* a}$ Thomas J. S. Schubert, ${ }^{b}$ Boyan Iliev ${ }^{b}$ and Frank Endres ${ }^{* a}$
}

\begin{abstract}
In this communication, we show that the combination of $1 \mathrm{M}$ lithium bis(trifluoromethylsulfonyl)amide and 1-butyl-1-methylpyrrolidinium bis(fluorosulfonyl)amide ( $\left.\mathrm{LiTFSI}_{\text {[ }} \mathrm{Py}_{1,4}\right] \mathrm{FSI}$ ) can be regarded as a possible stable electrolyte for IL based lithium ion batteries. We compare the charge-discharge results with the electrolyte 1 M LiTFSI in 1-butyl-1methylpyrrolidinium bis(trifluoromethylsulfonyl)amide ([Py $\left.y_{1,4}\right]$ TFSI) on an electrodeposited Ge electrode and show using a charge-discharge

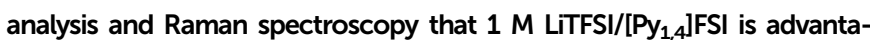
geous in maintaining the charge capacity as well as electrolyte stability at high current densities.
\end{abstract}

Ionic liquids are potential electrolytes for non-flammable lithium-ion batteries (LIBs). ${ }^{1,2}$ The properties of ionic liquids depend strongly on their molecular structure. Various combinations of ionic liquids have been investigated for different cathodic and anodic materials for a possible use in LIBs. ${ }^{2}$ A lot of research has focused mainly on using bis(trifluoromethylsulfonyl)amide (TFSI ${ }^{-}$) as an anion with various cations as the electrolyte, ${ }^{3-6}$ as this anion is supposed to form a good solid electrolyte interface (SEI).

Matsumoto et $a l^{7}$ first reported the use of a low viscosity ionic liquid with the bis(fluorosulfonyl)amide $\left(\mathrm{FSI}^{-}\right)$anion and showed a high cycling rate for a $\mathrm{Li} / \mathrm{LiCoO}_{2}$ test system. Later Sugimoto and Yamagata et al. showed that the LiTFSI/EMIFSI combination could provide a reversible capacity on a graphite electrode in lithium ion batteries without the need for an additive. $^{8,9}$ It was suggested that in LiTFSI/EMIFSI a stable SEI layer is achieved and combined with higher conductivity of the ionic liquid leads to good reversibility. ${ }^{9,10}$ A stable reversible capacity of $800 \mathrm{~mA} \mathrm{~h} \mathrm{~g}{ }^{-1}$ was also observed for the $\mathrm{Si}-\mathrm{Ni}-\mathrm{C}$ composite in ionic liquids with the FSI anion for lithium ion batteries. ${ }^{11}$ Different lithium salts were also added to 1-butyl-1methylpyrrolidinium bis(fluorosulfonyl)amide $\left(\left[\mathrm{Py}_{1,4}\right] \mathrm{FSI}\right)$ and

\footnotetext{
${ }^{a}$ Institute of Electrochemistry, Clausthal University of Technology, Arnold Sommerfeld Str 6, D-38678, Clausthal-Zellerfeld, Germany. E-mail: abhishek.lahiri@tu-clausthal.de,frank.endres@tu-clausthal.de

${ }^{b}$ IOLITEC Ionic liquids Technologies GmbH, Salzstrasse 184, D-74076, Heilbronn, Germany
}

the electrochemical properties were evaluated using a lithium metal electrode. Upon the addition of lithium salts to $\left[\mathrm{Py}_{1,4}\right] \mathrm{FSI}$, an extension in the cathodic limit was observed and the best cycling stability was found for $\mathrm{LiBF}_{4}$ in that ionic liquid. ${ }^{12}$

Binary and ternary ionic liquids have also been tested for batteries. LiFSI was added to $\left[\mathrm{Py}_{1,4}\right]$ TFSI and was evaluated as an electrolyte for a graphite electrode. It showed good cyclability close to the theoretical capacity at the $\mathrm{C} / 10$ charge rate at room temperature and a slightly elevated temperature of $55{ }^{\circ} \mathrm{C} .{ }^{13}$ Ternary electrolytes based e.g. on $\left[\mathrm{Py}_{1,4}\right] \mathrm{FSI}$ and $\left[\mathrm{Py}_{1,4}\right]$ TFSI containing $\mathrm{LiPF}_{6}$ were also tested for graphite electrodes, showing a wide electrochemical window and good stability at higher chargedischarge currents. ${ }^{14}$ Bayley et al. proposed a phase diagram using differential thermal analysis (DSC) for the binary ionic liquid electrolyte containing $\mathrm{FSI}^{-}$and $\mathrm{TFSI}^{-}$anions. From nuclear magnetic resonance (NMR) analysis, they showed that in the presence of the $\mathrm{FSI}^{-}$anion, the diffusivity of $\mathrm{TFSI}^{-}$ increases. The $\mathrm{Li}^{+}$ion diffusivity was also shown to increase in the mentioned binary ionic liquid. ${ }^{15}$

Here, we show that the ionic liquid electrolyte $1 \mathrm{M}$ LiTFSI/ $\left[\mathrm{Py}_{1,4}\right]$ FSI can be regarded as a potential stable electrolyte in LIBs and we have tested it on electrodeposited Ge as an anode host material. For lithium ion batteries, compared to $1 \mathrm{M} \mathrm{LiTFSI} /$ $\left[\mathrm{Py}_{1,4}\right]$ TFSI, quite a good reversible capacity was achieved in $1 \mathrm{M}$ LiTFSI/[Py $\left.y_{1,4}\right]$ FSI at rates of $0.5 \mathrm{C}$ and $1 \mathrm{C}$. Raman spectroscopy was performed to evaluate the stability of the ionic liquid before and after the charge-discharge cycles and also to understand the interactions between the lithium salt and the base ionic liquid.

The electrodeposition of germanium from $\left[\mathrm{Py}_{1,4}\right]$ TFSI has already been described in previous papers. ${ }^{16,17}$ Here, we electrodeposited germanium from $0.25 \mathrm{M} \mathrm{GeCl}_{4}-\left[\mathrm{Py}_{1,4}\right]$ TFSI on a copper substrate for 30 minutes. Fig. 1a compares the 1 st $\mathrm{CV}$ cycle of electrodeposited germanium in $1 \mathrm{M}$ LiTFSI in both $\left[\mathrm{Py}_{1,4}\right]$ FSI and $\left[\mathrm{Py}_{1,4}\right]$ TFSI ionic liquids. For $1 \mathrm{M}$ LiTFSI- $\left[\mathrm{Py}_{1,4}\right]$ FSI, reduction peaks are observed at $1.5 \mathrm{~V}$ and $1 \mathrm{~V}$ followed by a decrease in current from $0.5 \mathrm{~V}$ (black curve, Fig. 1a). The first two reduction peaks could be due to the underpotential deposition (UPD) of $\mathrm{Li}$ and formation of solid electrolyte interface (SEI) layers, respectively. 

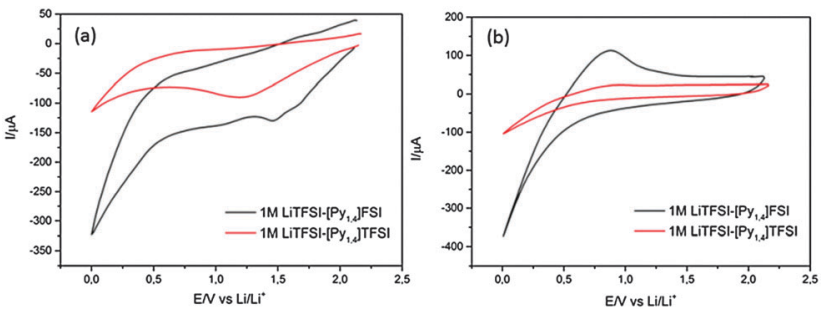

Fig. 1 (a) 1 st CV cycle of $1 \mathrm{M}$ LiTFSI in $\left[\mathrm{Py}_{1,4}\right] \mathrm{FSI}$ and $\left[\mathrm{Py}_{1,4}\right]$ TFSI on the electrodeposited Ge electrode. (b) 5 th $\mathrm{CV}$ cycle. Scan rate was $5 \mathrm{mV} \mathrm{s}^{-1}$ Temperature $=23^{\circ} \mathrm{C}$.

The decrease in the current is related to the intercalation of $\mathrm{Li}$ in the electrodeposited Ge. In comparison, with $1 \mathrm{M} \mathrm{LiTFSI-}$ $\left[\mathrm{Py}_{1,4}\right]$ TFSI a reduction process takes place at $1.25 \mathrm{~V}$ which could be the UPD of Li. The decrease in current from $0.25 \mathrm{~V}$ could be due to the intercalation of Li.

However, in the anodic scan no clear deintercalation peak is observed indicating some irreversibility in the first cycle. With an increase in the cycle number, the intercalation/deintercalation peaks became prominent. Fig. 1b shows the CV of the 5th cycle. A clear lithiation/delithiation peak is observed upon running the CV cycle with $1 \mathrm{M}$ LiTFSI-[Py $\left.{ }_{1,4}\right] \mathrm{FSI}$, whereas the lithiation/ delithiation peak is not that prominent in the case of $1 \mathrm{M}$ LiTFSI- $\left[\mathrm{Py}_{1,4}\right]$ TFSI. Furthermore, a higher current is achieved in the case of LiTFSI- $\left[\mathrm{Py}_{1,4}\right]$ FSI in both 1st and 5th cycles which could be related to lower viscosity and higher conductivity of the ionic liquid.

In order to test LiTFSI-[ $\left.\mathrm{Py}_{1,4}\right]$ FSI for a possible lithium-ion battery, galvanostatic charge-discharge cycles at rates of $1 \mathrm{C}$ and $0.5 \mathrm{C}$ were performed and compared with LiTFSI$\left[\mathrm{Py}_{1,4}\right]$ TFSI. In the lithium ion battery test, it was observed that with $1 \mathrm{M}$ LiTFSI-[Py $\left.\mathrm{P}_{1,4}\right] \mathrm{TFSI}$, the specific capacity at $1 \mathrm{C}$ was unstable in different experiments and therefore experiments were performed at a rate of 0.5 C. Fig. 2a shows 10 chargedischarge curves of electrodeposited Ge cycled at a rate of $1 \mathrm{C}$ in $1 \mathrm{M}$ LiTFSI- $\left[\mathrm{Py}_{1,4}\right]$ FSI. The first charge cycle obviously shows a greater charge of $1100 \mathrm{~mA} \mathrm{~h} \mathrm{~g}{ }^{-1}$ compared to the 2nd to 10th cycles, whereas the discharge cycle shows a slight activation with the cycle number. Fig. $2 \mathrm{~b}$ compares the charge-discharge cycles obtained at rates of $1 \mathrm{C}$ and $0.5 \mathrm{C}$ for $1 \mathrm{M}$ LiTFSI$\left[\mathrm{Py}_{1,4}\right]$ FSI and only $0.5 \mathrm{C}$ for $1 \mathrm{M}$ LiTFSI-[Py $\left.\mathrm{P}_{1,4}\right]$ TFSI. In $1 \mathrm{M}$ LiTFSI-[Py $\left.{ }_{1,4}\right]$ FSI, it is evident that the specific capacity decreases with the cycle number from $900 \mathrm{~mA} \mathrm{~h} \mathrm{~g}{ }^{-1}$ to about
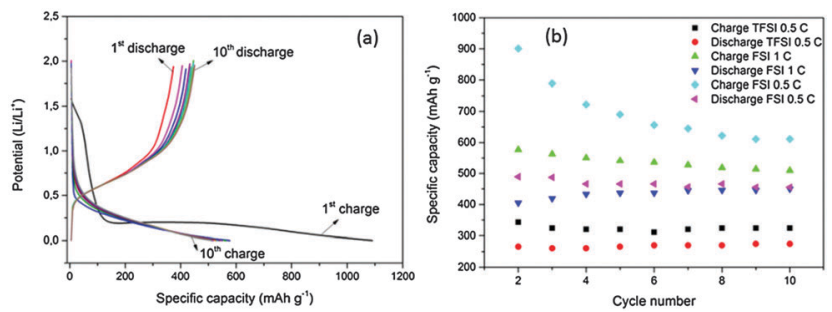

Fig. 2 (a) Charge-discharge curves of electrodeposited Ge cycled at $1 \mathrm{C}$ in $1 \mathrm{M}$ LiTFSI-[Py $\left.{ }_{1,4}\right] \mathrm{FSI}$. (b) Variation in specific capacity with the cycle number in both $\mathrm{TFSI}^{-}$and $\mathrm{TFSI}^{-} / \mathrm{FSI}^{-}$ionic liquids at different charge/discharge rates.
$650 \mathrm{~mA} \mathrm{~h} \mathrm{~g}^{-1}$ and $575 \mathrm{~mA} \mathrm{~h} \mathrm{~g}^{-1}$ to about $525 \mathrm{~mA} \mathrm{~h} \mathrm{~g}^{-1}$ for the 10 cycles at $0.5 \mathrm{C}$ and $1 \mathrm{C}$, respectively. However, the discharge capacity was almost constant at an average value of 425 and $445 \mathrm{~mA} \mathrm{~h} \mathrm{~g}^{-1}$, respectively.

In comparison, the charge-discharge capacity in $1 \mathrm{M}$ LiTFSI$\left[\mathrm{Py}_{1,4}\right]$ TFSI is rather low. The charge capacity on average was $325 \mathrm{~mA} \mathrm{~h} \mathrm{~g}^{-1}$ whereas the discharge capacity was $260 \mathrm{~mA} \mathrm{~h} \mathrm{~g}^{-1}$. The low specific capacity in the case of $1 \mathrm{M}$ LiTFSI-[ $\left.\mathrm{Py}_{1,4}\right]$ TFSI could be partly due to the higher viscosity, lower $\mathrm{Li}^{+}$diffusivity and poor formation of a solid-electrolyte interface. Sugimoto et $a .^{11}$ showed similar changes in specific capacity for the $\mathrm{Si}-\mathrm{Ni}-\mathrm{C}$ composite electrode when cycled in LiTFSI/EMIFSI and LiTFSI/EMITFSI wherein a high and stable reversible capacity of $800 \mathrm{~mA} \mathrm{~h} \mathrm{~g}{ }^{-1}$ was achieved in the TFSI/FSI binary electrolyte and no discharge capacity was achieved in the TFSI electrolyte.

For testing the stability of the ionic liquid, Raman spectroscopy was performed before and after charge-discharge cycles and the spectra are shown in Fig. 3. As the most significant signals of $\mathrm{TFSI}^{-}$and $\mathrm{FSI}^{-}$in Raman spectra occur between 700 and $800 \mathrm{~cm}^{-1}$, Fig. 3 shows only this region. The Raman peak of the pure TFSI ${ }^{-}$occurs at $741 \mathrm{~cm}^{-1}$ as marked in Fig. 3a. Upon addition of LiTFSI to $\left[\mathrm{Py}_{1,4}\right]$ TFSI, there is a decrease in peak intensity and a shift of the peak from $741 \mathrm{~cm}^{-1}$ to $746 \mathrm{~cm}^{-1}$ (red line, Fig. 3a). This lowering of intensity and shift in the peak are due to the formation of ion-pairs and aggregates between $\mathrm{Li}^{+}$and $\mathrm{TFSI}^{-}$, as reported in the literature. ${ }^{18-22}$ After 10 charge-discharge cycles at $0.5 \mathrm{C}$, the Raman intensity of the ionic liquid decreases (blue line, Fig. 3a).

In comparison, the Raman peak of pure $\mathrm{FSI}^{-}$occurs at $726 \mathrm{~cm}^{-1}$ (Fig. 3b). When $1 \mathrm{M}$ LiTFSI is added to $\left[\mathrm{Py}_{1,4}\right]$ FSI, a shoulder and a new peak appear at 730 and $745 \mathrm{~cm}^{-1}$, respectively (red line, Fig. 3b). It was recently shown that when LiFSI is added to $\left[\mathrm{Py}_{1,4}\right] \mathrm{FSI}$, the $\mathrm{FSI}^{-}$ peak intensity reduces and a new Raman band appears at $744 \mathrm{~cm}^{-1}$ which was deduced to be due to binding of $\mathrm{FSI}^{-}$to $\mathrm{Li}^{+}$ions and the formation of $\left[\mathrm{Li}(\mathrm{FSI})_{3}\right]^{2-} \cdot{ }^{23}$ As seen in Fig. $3 \mathrm{~b}$, a new peak is found at $745 \mathrm{~cm}^{-1}$ and with our instrumental resolution of $\pm 2 \mathrm{~cm}^{-1}$, this peak is due to the formation of aggregates and ion-pairs between $\mathrm{Li}^{+}$and $\mathrm{FSI}^{-}$. The shoulder at $729 \mathrm{~cm}^{-1}$ might be due to free $\mathrm{FSI}^{-}$or free $\mathrm{FTFSI}^{-}$which is solvated by $\left[\mathrm{Py}_{1,4}\right]^{+} .^{24,25}$ After 10 charge-discharge cycles, no reduction in intensity is found at the $745 \mathrm{~cm}^{-1}$ peak (blue line, Fig. $3 \mathrm{~b}$ ) whereas there is
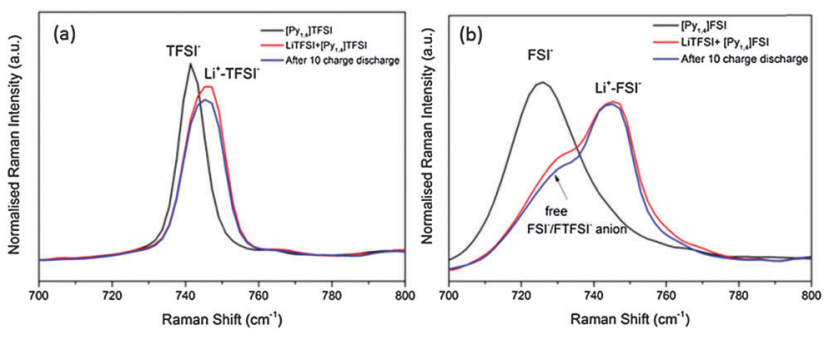

Fig. 3 (a) Comparison of Raman spectra between 700 and $800 \mathrm{~cm}^{-1}$ of

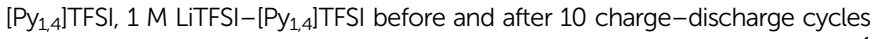
at $0.5 \mathrm{C}$. (b) Comparison of Raman spectra between 700 and $800 \mathrm{~cm}^{-1}$

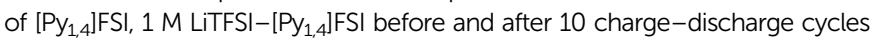
at $1 \mathrm{C}$. 

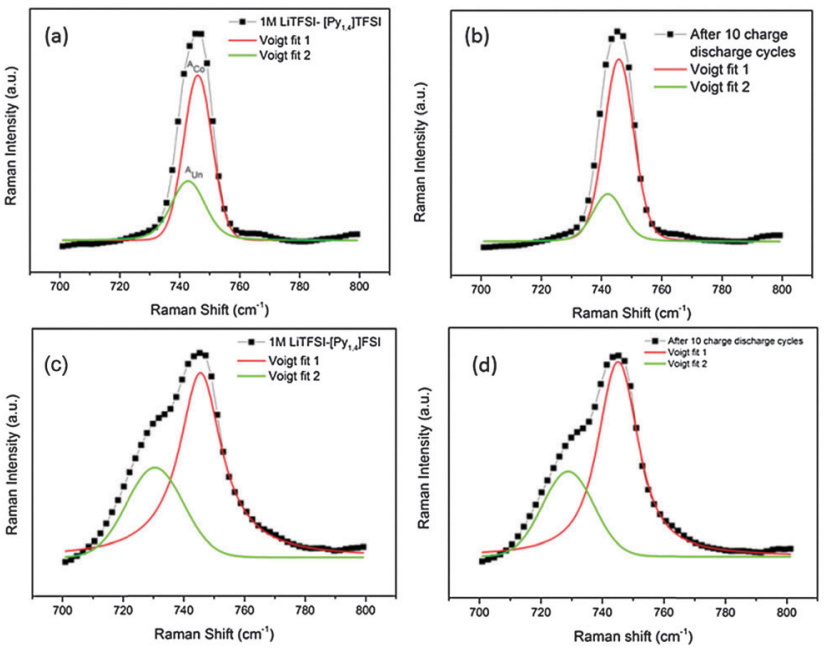

Fig. 4 (a) Voigt fit to the Raman spectra of 1 M LiTFSI-[Py $\left.y_{1,4}\right]$ TFSI, (b) after 10 charge-discharge cycles at $0.5 \mathrm{C}$, (c) $1 \mathrm{M}$ LiTFSI-[Py, $]$ FSI, (d) after 10 charge-discharge cycles at $1 \mathrm{C}$.

a decrease in the peak of the free anion at $729 \mathrm{~cm}^{-1}$. To obtain more quantitative information from the Raman spectra, the peaks were fitted with a Voigt function. Fig. 4 shows the peak fit of the ionic liquid before and after charge-discharge experiments. From these fits one can extract the average coordination number of the anion around the $\mathrm{Li}^{+}$ion according to eqn (1). ${ }^{22}$

$$
N=\frac{\frac{A_{\mathrm{Co}}}{\left(A_{\mathrm{Co}}+A_{\mathrm{Un}}\right)}}{x}
$$

Where $A_{\mathrm{Co}}$ is the coordinated $\mathrm{Li}^{+}$with TFSI/FSI, $A_{\mathrm{Un}}$ is the free anion and $x$ is the $\mathrm{Li}$ ion concentration. In Fig. 4a, for $1 \mathrm{M}$ LiTFSI- $\left[\mathrm{Py}_{1,4}\right]$ TFSI, $N$ was found to be 0.68 .

The coordination number has been shown to decrease from 6 to less than 1 with an increase in $\mathrm{Li}$ ion concentration in $\left[\mathrm{Py}_{1,4}\right]$ TFSI and was related to the formation of $\left[\operatorname{Li}(\mathrm{TFSI})_{y}\right]^{(y-1)}$ clusters. When the lithium concentration is between 0.08 and $0.2 \mathrm{M}$, the coordination number is 2 and lithium forms $\left[\mathrm{Li}(\mathrm{TFSI})_{2}\right]^{-22}$ For a $\mathrm{Li}$ ion concentration of $0.4 \mathrm{M}$ in $\mathrm{TFSI}^{-}$ ionic liquids, the coordination number was found to be less than 1 which was suggested to be due to the formation of aggregates such as $\left[\mathrm{Li}_{m}(\mathrm{TFSI})_{n}\right]^{(n-m)-}$ where $n / m<2$. . $^{22,25}$ It was further argued that from Raman spectroscopy it is not possible to differentiate between $\left[\mathrm{Li}(\mathrm{TFSI})_{y}\right]^{(y-1)}$ and $\left[\mathrm{Li}_{m}(\mathrm{TFSI})_{n}\right]^{(n-m)-} .^{25}$ As in our case the Li ion concentration in the electrolyte is $1 \mathrm{M}$, the coordination number is less than 1 and so we can say that the dominant species in the electrolyte is $\left[\mathrm{Li}_{m}(\mathrm{TFSI})_{n}\right]^{(n-m)-}$. However, we found that evaluating the coordination number gives hints towards the stability of the investigated electrolyte. The calculated coordination number of LiTFSI-[Py $\left.\mathrm{Py}_{1,4}\right]$ TFSI after 10 charge-discharge cycles in Fig. $4 \mathrm{~b}$ was found to increase to 0.79 from the original coordination number of 0.68 calculated from Fig. 4a. Furthermore, if we consider the ratio of the fitted peak area of the coordinated $\mathrm{Li}$ ion with $\mathrm{TFSI}^{-}$and free $\mathrm{TFSI}^{-}$ before and after charge-discharge processes, a change from $2.1 \pm 0.05$ to $3.7 \pm 0.05$ is observed. This suggests that there was some decomposition of the ionic liquid as well as an irreversible loss of lithium species during the intercalation/ deintercalation processes in $\left[\mathrm{Py}_{1,4}\right]$ TFSI. As it is known that the coordination number changes with LiTFSI concentration in the ionic liquid, the irreversible loss during charge-discharge/SEI layer formation processes might have led to a change in the coordination number. This assumption is further supported by the decrease in Raman intensity and the slight negative shift in the peak position after charge-discharge cycles in Fig. 3a. It has been shown by Howlett et al. ${ }^{26}$ using infrared spectroscopy that upon decomposition of $\mathrm{TFSI}^{-}$, there is only a reduction in the intensity peak and therefore the decrease in the Raman intensity in Fig. 3a could be related to the decomposition of the ionic liquid. In comparison, from Fig. $4 \mathrm{c}$ and $\mathrm{d}$, the coordination number for $1 \mathrm{M} \mathrm{LiTFSI} /\left[\mathrm{Py}_{1,4}\right]$ FSI was found to be 0.7 and after 10 charge-discharge cycles it was found to be 0.71 which is within the error limit. Furthermore, the ratio of the peak area of coordinated $\mathrm{Li}$ ions with $\mathrm{FSI}^{-}$and free $\mathrm{FSI}^{-}$before and after charge-discharge processes changes from $2.35 \pm 0.05$ to $2.47 \pm$ 0.05 , suggesting that this ionic liquid is relatively stable even at high charge-discharge currents. It was reported by Hardwick et $a .^{27}$ that from $0.5 \mathrm{M} \mathrm{LiTFSI} /\left[\mathrm{Py}_{1,3}\right] \mathrm{FSI}$, the decomposed product formed on $\mathrm{Li}$ metal was only from the reduction of TFSI $^{-}$and no products could be allocated to the $\mathrm{FSI}^{-}$anion. This supports our observation in Fig. 3b wherein no change in peak intensity is found at $745 \mathrm{~cm}^{-1}$ whereas a slight decrease in intensity is observed at $730 \mathrm{~cm}^{-1}$ indicating the possible decomposition of the FTFSI $^{-}$anion. It was shown from $a b$ initio calculation that interaction of $\mathrm{Li}^{+}$with $\mathrm{FSI}^{-}$is lower compared to that with $\mathrm{TFSI}^{-28}$ and therefore the $\mathrm{Li}^{+}$ion diffusivity will be higher in LiTFSI-[Py $\left.{ }_{1,4}\right]$ FSI compared to LiTFSI- $\left[\mathrm{Py}_{1,4}\right]$ TFSI. From Fig. 3b, $4 \mathrm{c}$ and $\mathrm{d}$ we can conclude that the vibration mode and the coordination number of $\mathrm{Li}^{+}$$\mathrm{FSI}^{-}$are not affected during charge-discharge cycles and therefore might have led to higher specific capacity of the LIB.

\section{Conclusions}

In this communication we have shown that LiTFSI/[Py $\left.y_{1,4}\right]$ FSI is a better ionic liquid for lithium ion batteries compared to LiTFSI/ $\left[\mathrm{Py}_{1,4}\right]$ TFSI with $\mathrm{Ge}$ as an anode host material. The charge and discharge capacity was found to be almost two times higher when using the LiTFSI-[Py $\left.\mathrm{Py}_{1,4}\right]$ FSI ionic liquid. Raman spectroscopy showed the appearance of a new peak and a shoulder upon addition of LiTFSI to $\left[\mathrm{Py}_{1,4}\right]$ FSI. After charge-discharge cycles, it was observed that there is decomposition in LiTFSI/[Py $\left.{ }_{1,4}\right]$ TFSI whereas LiTFSI/ $\left[\mathrm{Py}_{1,4}\right]$ FSI was found to be more stable.

\section{Experimental section}

The $\left[\mathrm{Py}_{1,4}\right]$ TFSI ionic liquid was purchased in the highest available quality from Io-Li-Tec (Germany) and was used after drying under vacuum at $100{ }^{\circ} \mathrm{C}$ to achieve a water content to be below 2 ppm. $\left[\mathrm{Py}_{1,4}\right]$ FSI was synthesized according to the literature. ${ }^{29,30} \mathrm{GeCl}_{4}$ (99.9999\%) was purchased from Alfa Aesar 
and LiTFSI (99.95\%) was purchased from Sigma Aldrich. The working electrode in the experiment was a copper plate. Prior to the experiments, the copper plate was cleaned with isopropanol and acetone to remove surface contaminations. Platinum wires were used as counter and quasi-reference electrodes which gave good stability for the ionic liquid throughout the experiments. The electrochemical cell was made of Teflon and clamped over a Teflon-covered Viton O-ring onto the substrate, yielding a geometric surface area of $0.3 \mathrm{~cm}^{2}$. Prior to the experiments, the Teflon cell and the O-ring were cleaned in a mixture of $50: 50 \mathrm{vol} \%$ of concentrated $\mathrm{H}_{2} \mathrm{SO}_{4}$ and $\mathrm{H}_{2} \mathrm{O}_{2}(35 \%)$ followed by refluxing in distilled water.

The electrochemical measurements were performed inside of an argon-filled glove box with water and oxygen contents below 2 ppm (OMNI-LAB from Vacuum Atmospheres) by using a VersaStat III (Princeton Applied Research) potentiostat/galvanostat controlled by powerCV and power-step software. The scan rate during cyclic voltammetry was $5 \mathrm{mV} \mathrm{s}^{-1}$.

For germanium deposition, a constant potential deposition was performed for 30 minutes from a solution of $0.25 \mathrm{M} \mathrm{GeCl}_{4}$ in $\left[\mathrm{Py}_{1,4}\right]$ TFSI. After the electrodeposition was done, the remaining ionic liquid in the cell was removed and the electrodeposited germanium was washed in the pure ionic liquid inside of the glove box. For testing the electrodeposited Ge electrode as an anode host material for lithium ion batteries, the Pt wires in the electrochemical cell were replaced by lithium foil which acted as both reference and counter electrodes, and $1 \mathrm{M}$ LiTFSI in $\left[\mathrm{Py}_{1,4}\right]$ TFSI and $\left[\mathrm{Py}_{1,4}\right]$ FSI, respectively, were used as electrolytes. After CV and charge-discharge cycles, the ionic liquid was stored in a sealed glass capillary for Raman analysis.

Raman spectra were recorded using a Raman module FRA 106 (Nd:YAG $1064 \mathrm{~nm}$ ) attached to a Bruker IFS 66v interferometer. For Raman analysis, the electrolyte was sealed in a glass capillary inside the glove box and the spectra were obtained at an average of 250 scans with a resolution of $2 \mathrm{~cm}^{-1}$. The spectra were fit to the Voigt function. The error in the ratio of peak area is obtained from different experiments performed and rounding of the values to two decimal places.

\section{Acknowledgements}

The authors thank DFG and BMBF (AlSiBat) for funding of the project. The authors also thank Mrs Karin Bode for help with Raman measurements.

\section{Notes and references}

1 M. Armand, F. Endres, D. R. MacFarlane, H. Ohno and B. Scrosati, Nat. Mater., 2009, 8, 621-629.

2 G. G. Eshetu, M. Armand, B. Scrosati and S. Passerini, Angew. Chem., Int. Ed., 2014, 53, 13342-13359.

3 Y. Abu-Lebdeh, A. Abouimrane, P.-J. Alarco and M. Armand, J. Power Sources, 2006, 154, 255-261.

4 V. Baranchugov, E. Markevich, E. Pollak, G. Salitra and D. Aurbach, Electrochem. Commun., 2007, 9, 796-800.

5 V. Borgel, E. Markevich, D. Aurbach, G. Semrau and M. Schmidt, J. Power Sources, 2009, 189, 331-336.
6 K. Tsunashima, F. Yonekawa and M. Sugiya, Electrochem. Solid-State Lett., 2009, 12, A54-A57.

7 H. Matsumoto, H. Sakaebe, K. Tatsumi, M. Kikuta, E. Ishiko and M. Kono, J. Power Sources, 2006, 160, 1308-1313.

8 T. Sugimoto, Y. Atsumi, M. Kikuta, E. Ishiko, M. Kono and M. Ishikawa, J. Power Sources, 2009, 189, 802-805.

9 M. Yamagata, Y. Matsui, T. Sugimoto, M. Kikuta, T. Higashizaki, M. Kono and M. Ishikawa, J. Power Sources, 2013, 227, 60-64.

10 M. Ishikawa and M. Yamagata, ECS Trans., 2013, 50, 217-327.

11 T. Sugimoto, Y. Atsumi, M. Kono, M. Kikuta, E. Ishiko, M. Yamagata and M. Ishikawa, J. Power Sources, 2010, 195, 6153-6156.

12 A. S. Best, A. I. Bhatt and A. F. Hollenkamp, J. Electrochem. Soc., 2010, 157, A903-A911.

13 M. Nadherna, J. Reiter, J. Moskon and R. Dominko, J. Power Sources, 2011, 196, 7700-7706.

14 G. B. Appetecchi, M. Montanino, A. Balducci, S. F. Lux, M. Winterb and S. Passerini, J. Power Sources, 2009, 192, 599-605.

15 P. M. Bayley, A. S. Best, D. R. MacFarlane and M. Forsyth, ChemPhysChem, 2011, 12, 823-827.

16 A. Lahiri, S. Zein El Abedin and F. Endres, J. Phys. Chem. C, 2012, 116, 17739-17745.

17 R. Al-Salman, S. Zein El Abedin and F. Endres, Phys. Chem. Chem. Phys., 2008, 10, 4650-4657.

18 J.-C. Lassegues, J. Grondin and D. Talaga, Phys. Chem. Chem. Phys., 2006, 8, 5629-5632.

19 Y. Umebayashi, T. Mitsugi, S. Fukuda, T. Fugimori, K. Fugii, R. Kanzaki, M. Takeuchi and S. I. Ighiguro, J. Phys. Chem. B, 2007, 111, 13028-13032.

20 A. Shirai, K. Fujii, S. Seki, Y. Umebayashi, S.-I. Ishiguro and Y. Ikeda, Anal. Sci., 2008, 24, 1291-1296.

21 Y. Umebayashi, H. Hamano, S. Seki, B. Minofar, K. Fujii, K. Hayamizu, S. Tzuzuki, Y. Kameda, S. Kohara and M. Watanabe, J. Phys. Chem. B, 2011, 115, 12179-12191.

22 J. Pitawala, J.-K. Kim, P. Jacobsson, V. Koch, F. Croce and A. Matic, Faraday Discuss., 2012, 154, 71-80.

23 K. Fujii, H. Hamano, H. Doi, X. Song, S. Tsuzuki, K. Hayamizu, S. Seki, Y. Kameda, K. Dokko, M. Watanabe and Y. Umebayashi, J. Phys. Chem. C, 2013, 117, 19314-19324.

24 G. A. Giffin, N. Laszczynski, S. Jeong, S. Jeremias and S. Passerini, J. Phys. Chem. C, 2013, 117, 24206-24212.

25 J.-C. Lassegues, J. Grondin, C. Aupetit and P. Johnsson, J. Phys. Chem. A, 2009, 113, 305-314.

26 P. C. Howlett, E. I. Izgorodina, M. Forsyth and D. R. Macfarlane, Z. Phys. Chem., 2006, 220, 1483-1498.

27 L. J. Hardwick, J. A. Saint, I. T. Lucas, M. M. Doeff and R. Kostecki, J. Electrochem. Soc., 2009, 156, A120-A127.

28 S. Tsuzuki, K. Hayamizu and S. Seki, J. Phys. Chem. B, 2010, 114, 16329-16336.

29 M. Armand, M. Gauthier, C. Michot and N. Ravet, WO Pat., 9940025, 1999.

30 R.-S. Kühnel and A. Balducci, J. Power Sources, 2014, 249, 163-171. 